iss

\title{
Are we in the "V" Or The "T"? Community Paediatricians' Experiences of working with Child And Adolescent Mental Health Services in Managing Common Childhood Conditions
}

\section{Hani Ayyash ${ }^{1}$, Michael Ogundele ${ }^{2}$, Tanja-Sabine Schumm ${ }^{3}$, Richard Lynn ${ }^{4}$, Oana Mitrofan ${ }^{5}$}

\author{
1.Integrated Child Health Dept, Cambridgeshire and Peterborough NHS Foundation Trust, UK \\ 2.Community Paediatrics, NHS Fife, Glenrothes, Scotland \\ 3.NHS Greater Glasgow \& Clyde, CAMHS, Glasgow UK \\ 4.British Paediatric Surveillance Unit, Royal College of Paediatrics and Child Health, UK \\ 5.University of Exeter Medical School and Health Education South West (Peninsula), UK
}

\section{Background}

In the UK, Community Paediatric and Child and Adolescent Mental Health (CAMH) services are often involved in managing neuro-developmental and psychiatric conditions in children and young people. Recent governmental policies emphasized more horizontal integration of multidisciplinary agencies working with children with mental health problems, but nationwide data on the level of service integration, its challenges and impact on patient care are limited.

\section{Results}

- 245 Paediatricians completed the survey and provided additional information in free text.

- The data suggests a great variation in service provision depending on geographical location, child age and diagnosis. Collaborative work tends to be infrequent, informal and condition specific. The majority of paediatricians report minimal joint working with compartmentalised Paediatric and CAMH services.

- Thematic analysis suggests that collaborative working leads to more positive outcomes whilst separate working could lead to patients 'falling through the gaps'.

- Identified barriers to integration were lack of staff and resources and high referral thresholds.

\section{Conclusion}

Despite the suggestion that the collaborative model would lead to better patient care, integration of paediatric and CAMH services in the UK is currently limited, with most services working separately (the "V" model) rather than collaboratively (the " $T$ " model).

\section{References}

1. Five year forward view.

NHS England. 2014.

Presented at the 7th Congress of the European Academy of Paediatric Societies

\section{Methods}

We aimed to explore the experiences of Community

Paediatricians working jointly with local CAMH services in the assessment and management of neuro-developmental and psychiatric conditions.

We conducted a survey using the Child and Adolescent Psychiatric Surveillance System by distributing a semistructured questionnaire through the British Association for Community Child Health newsletters and direct mass-emailing to members across 180 UK Community Child Health units.

Both quantitative and qualitative methods via thematic analysis were employed to analyse the data.

Table showing different areas of Community Child Health involvement of the respondents

\begin{tabular}{|l|c|c|}
\hline Areas of involvement & $\begin{array}{c}\text { Percent (\%) } \\
\mathbf{N = 2 2 7}\end{array}$ & $\begin{array}{c}\text { No. } \\
\text { Respondents }\end{array}$ \\
\hline $\begin{array}{l}\text { Neurodevelopmental (including ADHD and } \\
\text { ASD) }\end{array}$ & $\mathbf{7 0 . 4 8 \%}$ & $\mathbf{1 6 0}$ \\
\hline Neurodisability - Epilepsy, sleep, sensory & $\mathbf{5 0 . 2 2 \%}$ & $\mathbf{1 1 4}$ \\
\hline Safeguarding/Child Protection & $\mathbf{4 2 . 7 3 \%}$ & $\mathbf{9 7}$ \\
\hline Behavioural Paediatrics & $\mathbf{3 2 . 6 0 \%}$ & $\mathbf{7 4}$ \\
\hline Looked After Children & $\mathbf{2 9 . 9 6 \%}$ & $\mathbf{6 8}$ \\
\hline $\begin{array}{l}\text { Other (e.g Genetics, Research, Continence, } \\
\text { SEND, Palliative) }\end{array}$ & $\mathbf{2 2 . 9 1 \%}$ & $\mathbf{5 2}$ \\
\hline Foetal Alcohol Syndrome & $\mathbf{1 7 . 6 2 \%}$ & $\mathbf{4 0}$ \\
\hline
\end{tabular}

Table showing Variable degree of CAMHS integration / joint working
Level of joint-working

Specific conditions eg. ASD, complex

ADHD, LD

Informal Discussions

Regular Joint-CAMHS work

Joint - Psychologist work

Discontinued joint work

Planned joint work

\section{Acknowledgements}

We are grateful to all CAPSS, BPSU and

BACCH Executive Committee Members for

their encouragement \& support for this
Response (\%)

$n=117$

34 (29\%)

13 (11\%)

$12(10 \%)$

$7(6 \%)$

$7((6 \%)$

$2(1.7 \%)$ 